\title{
The effects of multimedia advertising on building brand equity
}

\author{
Reza Pirayesh $^{\mathrm{a}^{*}}$ and Masoud Ghaempanah ${ }^{\mathrm{b}}$
}

${ }^{a}$ Assistant Professor, Department of Management and Accounting, University of Zanjan, Zanjan, Iran ${ }^{b}$ Masters of Business Administration

\section{H R O N I C L E}

Article history:

Received January 22, 2014

Accepted 7 July 2014

Available online

July $8 \quad 2014$

Keywords:

Brand equity

Multimedia advertisement

Banking industry \begin{abstract}
A B S T R A C T
This paper presents an empirical investigation to study the effects of multimedia advertisement on building brand equity. The proposed study uses two questionnaires, one for multimedia advertisement, which consists of 17 questions and the other one for measuring brand equity. The survey is applied among 384 randomly selected customers who do their daily businesses with banks located in province of Kordestan, Iran. Using Pearson correlation as well as linear regression techniques, the study has determined a positive and meaningful relationship between these two variables. In our survey, word of mouth advertisement seems to have the highest impact on brand equity followed by having seminars.
\end{abstract}

\section{Introduction}

In banking industry, there is always a need to build good brand equity to help the industry grow. Multimedia advertisement is one of the most popular techniques for introducing business activities (Horowitz \& Rudolph, 2004; Apte \& Roesler, 2007). There are many studies on measuring the effects of this type of marketing on business development. Vakratsas and Ma (2005), for instance, investigated the long-term effectiveness of multimedia advertising in a competitive setting and its implementation for budget allocation decisions, using multivariate persistence methodology. Fitzgerald (2004) reported that retail store visits was associated with media advertising exposure and can increase return of investment. Mei and Hua (2010) summarized the existing trend of Internet multimedia advertising and built a broad survey on the techniques for advertising driven by the rich contents of images and videos. They explained three key problems in a generic multimedia advertising framework including contextual relevance, contextual intrusiveness and insertion optimization. They presented recently developed MediaSense, which includes of image, video, and game advertising as an exemplary application of contextual multimedia advertising. In the MediaSense, the most contextually relevant ads were embedded at the most appropriate positions within images or videos. They also leveraged techniques in computer vision, multimedia retrieval, and computer human interaction.

*Corresponding author. Tel: +98 2415152290

E-mail addresses: r_pirayesh@znu.ac.ir (R.Pirayesh) 
Azad et al. (2012) applied a questionnaire-based survey to determine the most important factors influencing advertisement by focusing on gathering information from the advertisement providers to evaluate each advertisement plan. Chuang and Chong (2004) described that a good advertisement ought to select appropriate perspectives in terms of color, dimension and the content to affect end line customers, profoundly. Patsioura et al. (2009) built an effectiveness conceptual framework to evaluate the overall performance of corporate advertising web sites towards the multiple advertising, promotional and relationship marketing goals of their establishment. They investigated communication, feedback and customer support policies to determine their contribution in creating or affecting advertising "effects". They reported the significant dimensions of the participants' behavior based on their actions, activities, preferences and intentions.

\section{The proposed study}

This paper presents an empirical investigation to study the effects of multimedia advertisement on building brand equity. The proposed study uses two questionnaires, one for multimedia advertisement, which consists of 17 questions including using experts (3 questions), having seminars (5 questions), word of mouth advertisement (3 questions), referred sales (2 questions) and networking (4 questions). In addition, the questionnaire of brand equity (Aaker, 2008, 2009, 2012; Keller, 1993) consists of four section including quality perception (4 questions), brand awareness (2 questions), customer loyalty (5 questions) and brand associate (4 questions). The survey is applied among randomly selected customers who do business with banks located in province of Kordestan, Iran. Therefore, the sample size is calculated as follows,

$N=Z_{\alpha / 2}^{2} \frac{p \times q}{e^{2}}$,

where $N$ is the sample size, $p=1-q$ represents the probability, $z_{\alpha / 2}$ is CDF of normal distribution and finally $\varepsilon$ is the error term. For our study, we assume $p=0.5, z_{\alpha / 2}=1.96$ and $e=0.05$, the number of sample size is calculated as $N=384$. The main hypthesis of the survey is as follows,

Main hypothesis: There is a meaningful relationship between multimedia advertisement and brand equity.

The main hypothesis itself consists of the following five sub-hypotheses,

1. There is a meaningful relationship between the amount of experts' contribution and brand equity.

2. There is a meaningful relationship between having Seminars and brand equity.

3. There is a meaningful relationship between word of mouth advertisement and brand equity.

4. There is a meaningful relationship between referred sales and brand equity.

5. There is a meaningful relationship between networking and brand equity.

Before, applying the survey, we have distributed 30 questionnaires among some selected experts and measured Cronbach alphas summarized in Table 1 as follows,

Table 1

The summary of Cronbach alphas

\begin{tabular}{lclc}
\hline Variable & Cronbach alpha & Variable & Cronbach alpha \\
\hline Experts' contribution & 0.887 & Perception quality & 0.810 \\
Seminars & 0.803 & Brand awareness & 0.752 \\
Mouth advertisement & 0.796 & Brand loyalty & 0.763 \\
Referred sales & 0.846 & Brand associate & 0.729 \\
Networking & 0.713 & Brand equity & 0.811 \\
\hline
\end{tabular}


As we can observe from the results of Table 1, all components of the survey are well above the minimum desirable level of 0.70. Therefore, we can distribute the questionnaire among all 384 participants of the survey. The implementation of Kolmogorov-Smirnov test confirms that all components of the survey are normally distributed. Therefore, we use Pearson correlation test as well as linear regression technique to examine various hypotheses of the survey.

\section{The results}

In this section, we present details of our findings on testing all hypotheses of the survey.

\subsection{The main hypothesis: The relationship between multimedia advertisement and brand equity}

The main hypothesis of the survey investigates whether there is a positive and meaningful relationship between multimedia advertisement and brand equity. In our survey, Pearson correlation is equal to 0.564 with Sig. $=0.000$. In addition, the regression model also yields a positive relationship between these two components and Adjusted R-Square is equal to 0.32. Therefore, we can confirm the main hypothesis of the survey.

\subsubsection{The first sub-hypothesis: The effects of experts' insights on brand equity}

The first sub-hypothesis of the survey investigates whether or not there is a positive and meaningful relationship between experts' insights and brand equity. In our survey, Pearson correlation is equal to 0.496 with Sig. $=0.000$. In addition, the regression model also yields a positive relationship between these two components and Adjusted R-Square is equal to 0.25. Therefore, we can confirm the first hypothesis of the survey.

\subsubsection{The second sub-hypothesis: The effects of having seminars on brand equity}

The second sub-hypothesis of the survey studies whether or not there is a positive and meaningful relationship between having informative seminars as well as video conferences and brand equity. In our study, Pearson correlation is equal to 0.513 with Sig. $=0.000$. Besides, the regression model also provides a positive relationship between these two figures and Adjusted R-Square is equal to 0.26, which brings us to confirm the second hypothesis.

\subsubsection{The third sub-hypothesis: The effects of word of mouth advertisement on brand equity}

The third sub-hypothesis of the investigation looks to find out whether or not there is a positive and meaningful relationship between word of mouth advertisement and brand equity. In our investigation, Pearson correlation is equal to 0.402 with Sig. $=0.000$. Moreover, the regression model also gives us a positive relationship between these two variables and Adjusted R-Square is equal to 0.16, which leads us to conclude that word of mouth advertisement influences positively on brand equity.

\subsubsection{The fourth sub-hypothesis: The effects of referred sales on brand equity}

The fourth sub-hypothesis of the survey attempts to find out whether or not there is a positive and meaningful relationship between referred sales and brand equity. Pearson correlation is equal to 0.896 with Sig. $=0.000$, the regression model also leads us to get a positive relationship between these two figures and Adjusted R-Square is equal to 0.80, which means we may confirm the fourth hypothesis.

\subsubsection{The fifth sub-hypothesis: The effects of networking on brand equity}

Finally, the last sub-hypothesis of the survey tries to find out whether or not there is a positive and meaningful relationship between networking and brand equity. In our study, Pearson correlation is equal to 0.321 with Sig. $=0.000$. In addition, the regression model also indicates a positive relationship between these two variables and Adjusted R-Square is equal to 0.10, which leads us to confirm the last hypothesis. 


\section{Conclusion}

In banking industry, there is always a need to build good brand equity to help the industry grow. In this paper, we have presented an empirical investigation to study the relationship between multimedia advertisement and brand equity in Iranian banking industry. Using Pearson correlation as well as linear regression techniques, the study has determined a positive and meaningful relationship between these two variables. In our survey, word of mouth advertisement seems to have the highest impact on brand equity followed by having seminars. The results of this study are consistent with findings earlier published by Azad et al. (2012), Chuang and Chong (2004) and Mei and Hua (2010).

\section{Acknowledgement}

The authors would like to thank the anonymous referees for constructive comments on earlier version of this paper.

\section{References}

Aaker, D. A. (2008). Strategic market management. John Wiley \& Sons.

Aaker, D. A. (2009). Managing brand equity. Simon and Schuster.

Aaker, D. A. (2012). Building strong brands. Simon and Schuster.

Apte, J., \& Roesler, M. L. (2007). U.S. Patent No. 7,225,142. Washington, DC: U.S. Patent and Trademark Office.

Azad, N., Aliakbar, S., \& Kordalivand, N. (2012). Investigating effective factors on multimedia advertising: A case study of travel agencies. Management Science Letters, 2(1), 409-416.

Chuang, T.T., \& Chong, P. P. (2004). Searching advertising placement in cyberspace. Industrial Management \& Data Systems, 104(2), 144-148.

Fitzgerald, J. (2004). Evaluating return on investment of multimedia advertising with a single-source panel: A retail case study. Journal of Advertising Research, 44(03), 262-270.

Horowitz, D., \& Rudolph, B. (2004). U.S. Patent Application 10/974,323.

Keller, K. L. (1993). Conceptualizing, measuring, and managing customer-based brand equity. The Journal of Marketing, 57(1), 1-22.

Mei, T., \& Hua, X. S. (2010). Contextual internet multimedia advertising. Proceedings of the IEEE, 98(8), 1416-1433.

Patsioura, F., Vlachopoulou, M., \& Manthou, V. (2009). A new advertising effectiveness model for corporate advertising web sites: a relationship marketing approach. Benchmarking: An International Journal, 16(3), 372-386.

Vakratsas, D., \& Ma, Z. (2005). A look at the long-run effectiveness of multimedia advertising and its implications for budget allocation decisions. Journal of Advertising Research, 45(02), 241-254. 